\title{
Raf Kinase Inhibitory Protein Down- Expression Exacerbates Hepatic Fibrosis In Vivo and In Vitro
}

\author{
Quanfang Huang ${ }^{a}$ Chunhong Liang ${ }^{b}$ Ling Wei $^{b}$ Jinlan Nie ${ }^{b}$ Shengjuan Lu $^{b}$ \\ Chunyuan Lu ${ }^{b}$ Lang Zhuoc ${ }^{c}$ Zhongpeng Lua,d Xing Lin ${ }^{b}$
}

${ }^{a}$ The First Affiliated Hospital of Guangxi University of Chinese Medicine, Nanning, China; ${ }^{b}$ Guangxi Medical University, Nanning, China; 'Institute of Bioengineering and Nanotechnology, Singapore, Singapore; ${ }^{d}$ Department of Biochemistry, University of Arkansas Medical School, Little Rock, USA

\section{Key Words}

RKIP • Locostatin • ERK pathway $\bullet$ TLR4 pathway $•$ Hepatic fibrosis

\begin{abstract}
Background/Aims: Raf kinase inhibitory protein (RKIP) is closely associated with numerous tumors and participates in their development through regulating the growth, apoptosis, invasion and metastasis of tumor cells. However, the role of RKIP in chronic liver injury and particularly in liver fibrosis is still unclear. Methods: In the present study, hepatic fibrosis was induced by porcine serum (PS) in rats and primary hepatic stellate cells (HSCs) were isolated from rat livers. Moreover, locostatin was used to interfere with RKIP expression. Results: RKIP expression was significantly inhibited by locostatin in both liver tissues of rats and primary HSCs. Down-regulating RKIP expression resulted in serious liver injury, extensive accumulation of collagen, and significant increase in the levels of ALT, AST and TNF- $\alpha$ during liver fibrosis in rats. Moreover, down-regulating RKIP significantly promoted HSCs proliferation and colony formation in vitro. Reduced RKIP significantly increased the production of collagen and the level of $\alpha$-SMA as well as the expression of MMP- 1 and MMP- 2 in both liver tissues and primary HSCs. Furthermore, down-regulating RKIP promoted the activation of the ERK and TLR4 signaling pathways. Conclusion: Our findings clearly indicate an inverse correlation between RKIP level and the degree of the liver injury and fibrosis. The decrease in RKIP expression may exacerbate chronic liver injury and liver fibrosis.
\end{abstract}

(C) 2016 The Author(s)

Published by S. Karger AG, Basel

\section{Introduction}

Hepatic fibrosis is a common feature of chronic liver diseases, and is characterized by excessive accumulation of extracellular matrix (ECM) [1]. Extensive and persistent hepatic fibrosis results in cirrhosis, liver failure, and portal hypertension and has for a long time been considered irreversible [2]. Proliferation and activation of hepatic stellate cells (HSCs) is a key step in the development of liver fibrosis; targeting the proliferation of HSCs has been 


\section{Cellular Physiology Cell Physiol Biochem 2016;40:49-61 \begin{tabular}{ll|l}
\cline { 2 - 2 } and Biochemistry $10.1159 / 000452524$ & $\begin{array}{l}\text { @ 2016 The Author(s). Published by S. Karger AG, Basel } \\
\text { www.karger.com/cpb }\end{array}$ \\
\hline
\end{tabular} Huang et al.: Role of RKIP in Hepatic Fibrosis}

considered as a novel therapeutic strategy for treating liver fibrosis [3]. It has been reported that the extracellular signal-regulated kinases (ERK)/mitogen-activated protein kinase (MAPK) signaling pathway is involved in the proliferation of HSCs and the ECM synthesis in activated HSCs; this signal pathway has been found to play an important role in hepatic fibrosis [4].

Raf kinase inhibitor protein (RKIP) is a conserved cytosolic protein with wide tissue expression and does not share significant homology with other kinase inhibitors [5]. RKIP directly interacted with both Raf- 1 and MEK and disrupted the Raf-1/MEK interaction, thereby preventing the activation of MEK and downstream components of the signaling cascade. Over-expression of RKIP suppressed ERK/MAPK signaling, and down-regulation of RKIP had the opposite effect [6]. Although the molecular mechanism by which RKIP inhibits the ERK/MAPK signaling pathway has been partially delineated, little is known about the role of RKIP in liver fibrogenesis and how RKIP may be regulated in hepatic stellate cells. In the present study, porcine serum (PS) - induced hepatic fibrosis was used as a unique model of liver fibrosis, and primary hepatic stellate cells that were isolated from rats livers were used as an experimental cell model of activated HSCs. The biological role of RKIP on the aggressiveness of liver fibrosis was assessed in vivo and in vitro.

\section{Materials and Methods}

Hepatic fibrosis induced by porcine serum in rats

Male Sprague Dawley rats, weighting 150-160 g, were obtained from Guangxi Medical University Experimental Animal Center (Guangxi, China). This study was conducted according to the protocols approved by Guangxi Medical University Institutional Ethical Committee.

Hepatic fibrosis was induced by porcine serum (PS) in rats as previously described [7]. In brief, 48 rats were randomly divided into 4 groups (12 rats/group) including normal control group, locostatin (a specific inhibitor of RKIP) control group, PS model group, and PS + locostatin group. The rats in the locostatin control group were administrated locostatin $(0.5 \mathrm{mg} / \mathrm{kg})$ (Merck, Darmstadt, Germany) by intraperitoneal injection, while the normal control rats received equivalent normal saline once a day for 18 weeks. The animals in the PS model group and the PS + locostatin group received $0.5 \mathrm{ml}$ porcine serum (Gibco, USA) intragastrically twice a week for 18 weeks. In addition to PS, rats in the PS + locostatin group received 0.5 $\mathrm{mg} / \mathrm{kg}$ locostatin by intraperitoneal injection once a day for 18 weeks. All rats were sacrificed at the end of treatment. Blood and liver samples were obtained for further examination.

\section{Histopathological examination}

The livers were fixed in $10 \%$ formalin, embedded in paraffin, cut into $5-\mu \mathrm{m}$ sections and mounted on glass slides. Samples were stained with hematoxylin-eosin (H\&E) and Masson's trichrome. Histopathological changes were observed under a light microscope $[8,9]$.

\section{Serological tests}

The serum levels of alanine transaminase (ALT) and aspartate transaminase (AST) were measured using commercial kits (Nanjing Jiancheng Institute of Biotechnology, Nanjing, China). TNF- $\alpha$ in the plasma was detected using an enzyme-linked immunosorbent assay kit (Beijing Yonghui Biological Technology, Beijing, China).

\section{Determination of Hepatic fibrotic indicators}

The levels of hepatic hydroxyproline (Hyp), precollagen type III (PCIII), laminin (LN) and hyaluronic acid (HA) were determined using commercially available kits (North Institute of Biotechnology, Beijing, China) according to the manufacturer's instructions.

Immunohistochemistry analysis

Liver tissues were fixed in $10 \%$ formalin and embedded in paraffin. The 5 - $\mu$ m sections were then deparaffinized and treated with $0.3 \%$ endogenous peroxidase blocking solution for 20 min. Sections were 


\section{Cellular Physiology Cell Physiol Biochem 2016;40:49-61 \begin{tabular}{ll|l} 
and Biochemistry & Published online: November 14, 2016 & $\begin{array}{l}\text { ○ } 2016 \text { The Author(s). Published by S. Karger AG, Basel } \\
\text { www.karger.com/cpb }\end{array}$ \\
\hline
\end{tabular} Huang et al.: Role of RKIP in Hepatic Fibrosis}

treated sequentially with normal goat serum for $20 \mathrm{~min}$ and incubated with primary antibodies including RKIP, ERK and p-ERK (1:100 dilution, Santa Cruz) at $4{ }^{\circ} \mathrm{C}$ for $24 \mathrm{~h}$. Biotin-labeled anti-rabbit immunoglobulin $\mathrm{G}$ was incubated for $30 \mathrm{~min}$ at room temperature. Detection of immunoreactivity was performed by the streptavidin-biotin method using horseradish peroxidase and diaminobenzidine as the chromogen (Histostain Kit; Zymed, San Francisco, CA). Sections were counterstained using hematoxylin (Zymed) and examined under light microscopy.

\section{Hepatic stellate cells isolation and culture}

Hepatic stellate cells were isolated from livers of male Sprague Dawley rats (400-500 g) as previously described [10]. Cell viability (95\%) was assessed by the Trypan blue exclusion method and purity of the HSC fraction (97\%) was determined according to the previous study [11]. All cells were cultured in DMEM medium in the presence of $20 \%$ fetal calf serum at $37^{\circ} \mathrm{C}$ in $5 \% \mathrm{CO}_{2}$ for $48 \mathrm{~h}$.

Next, the freshly isolated HSCs were plated at a density of $5 \times 10^{5}$ cells $/ \mathrm{ml}$ on uncoated plastic dishes. After a 5-day culture period, the primary HSCs were divided into four groups including normal control cells, locostatin control cells (cells were treated with $50 \mu \mathrm{M}$ locostatin [12]), PDGF-BB-treated cells (cells were incubated with $10 \mathrm{nM}$ PDGF-BB [13]), and PDGF-BB + locostatin-treated cells (cells were treated with $10 \mathrm{nM}$ PDGF-BB plus $50 \mu \mathrm{M}$ locostatin). HSCs were incubated with corresponding reagents for $48 \mathrm{~h}$ and were then used in the following cell experiments.

\section{Cell proliferation assay}

Cell proliferation was evaluated using a 3-(4, 5-dimethylthiazol-2-yl)-2,5-diphenyltetrazolium bromide (MTT, Sigma Chemical Co., USA) assay $[14,15]$. The absorbance was determined at a $570 \mathrm{~nm}$ wavelength, with a reference wavelength of $630 \mathrm{~nm}$. The results are presented as the average absorbance of six wells in one experiment, and the assays were performed in triplicate.

Clonogenicity assay

Cells were seeded in a fresh six-well plate $\left(1 \times 10^{3}\right.$ cells/well) with methylcellulose medium (STEMCELL Technologies, Vancouver, Canada). The colonies were counted 7 days later.

\section{Measurement of intracellular collagen content}

Intracellular collagen was measured by a Sirius Red-based colorimetric assay [16]. Briefly, cells were washed with phosphate buffered saline (PBS) twice and then fixed with Bouin's fluid for $1.5 \mathrm{~h}$. After fixation, the fixation fluid was removed. The culture dishes were washed by immersion in running tap water for 15 min and were air dried. Cells were stained with Sirius Red dye reagent for $1 \mathrm{~h}$ on a rocker with a speed of 5 rpm. Thereafter, the solution was removed and the cultures were washed with $0.01 \mathrm{~N} \mathrm{HCl}$ to remove nonbound dye. The stained material was dissolved in $0.1 \mathrm{~N} \mathrm{NaOH}$ and the absorbance were measured at $550 \mathrm{~nm}$ against $0.1 \mathrm{~N} \mathrm{NaOH}$ as a blank.

\section{$R T$ - PCR assay}

Total RNA was prepared using a TRIzol kit (Invitrogen, CA, USA) and was reverse-transcribed to complementary DNA (cDNA) using a High Capacity RNA-to-cDNA kit (Applied Biosystems Inc., Foster City, CA, USA). Gene expression levels were estimated by quantitative real-time PCR using the StepOnePlus realtime PCR system (Applied Biosystems) with Fast SYBR Green master mix (Applied Biosystems). The primers used in this study are listed in Table 1 . The relative gene expression was measured using glyceraldehyde3-phosphate dehydrogenase (GAPDH) as an internal control. The relative amount of target mRNA in each sample was calculated using the DDCt method [17].

\section{Western blot analysis}

The whole cell proteins were prepared using RIPA buffer (Thermo Fischer Scientific, Inc., Waltham, MA) [18], and the total hepatic proteins were extracted from liver tissues using radioimmunoprecipitation buffer (Sigma-Aldrich). The content of protein was determined using a bicinchoninic acid protein assay kit (Thermo Scientific, Rockford, IL, USA). Proteins were assayed using a Gel Doc XR gel imaging system (BioRad). Protein samples were separated by SDS-PAGE and transferred to polyvinylidene difluoride membranes (Millipore, Bedford, MA, USA) for $2 \mathrm{~h}$ at $100 \mathrm{~V}$. The membranes were then incubated overnight at $4^{\circ} \mathrm{C}$ 


\section{Cellular Physiology Cell Physiol Biochem 2016;40:49-61 \begin{tabular}{ll|l}
\cline { 2 - 2 } and Biochemistry & Published online: November 14, 2016 & $\begin{array}{l}\text { ○ } 2016 \text { The Author(s). Published by S. Karger AG, Basel } \\
\text { www.karger.com/cpb }\end{array}$ \\
\hline
\end{tabular} Huang et al.: Role of RKIP in Hepatic Fibrosis}

under agitation with the following primary antibodies: RKIP, Raf, p-Raf, MEK, p-MEK, ERK, p-ERK, collagen I, $\alpha$-SMA, MMP-1, MMP-2 and TLR4 (Santa Cruz Biotechnology). The membranes were subsequently incubated with secondary antibody for $2 \mathrm{~h}$ at room temperature. The immune complexes were detected using enhanced chemiluminescence western blotting reagents (Sinopharm Chemical Reagent, Shanghai, China). The detected proteins were normalized to $\beta$-actin (Santa Cruz Biotechnology) or the respective total protein, as appropriate [19].

\section{Statistical analysis}

Statistical analysis was performed using SPSS 11.5 for Windows. Differences between the groups were assessed using a oneway analysis of variance (ANOVA) with a Tukey's test for post hoc multiple comparisons. The data are presented as the means \pm SD. A p-value $<0.05$ was considered to be statistically significant.

\section{Results}

The expression of RKIP in liver tissues and primary HSCS

To investigate the role of RKIP in hepatic fibrosis, locostatin was used to interfere with RKIP expression in hepatic tissues and primary HSCs. As shown in Fig. 1A, the immunohistochemical analysis showed that majority of RKIP localized in the cytoplasm of hepatic cells. Compared to the PS model group, the intensity of RKIP-positive cells was significantly decreased in the PS + locostatin group.

Table 1. The sequences of primers used for real-time quantitative PCR

\begin{tabular}{lll}
\hline Gene & Forward $\left(5^{\prime}-3^{\prime}\right)$ & Reverse $\left(5^{\prime}-3^{\prime}\right)$ \\
\hline Collagen I & CAGTCGCTTCACCTACAGCA & GGTGGAGGGAGTTACACGA \\
$\alpha$-SMA & AGGCACCCCTGAACCCCAA & CAGCACCGCCTGGATAGCC \\
MMP-1 & TGATATCGGGGCTTTGATGT & CACTTCTCCCCGAATCGTAG \\
MMP-2 & TCCCATTTTGATGACGATGA & CCGTACTTGCCATCCTTCTC \\
TLR4 & TGCTCAGACATGGCAGTTTC & TCAAGGCTTTTCCATCCAAC \\
MyD88 & GAGATCCGCGAGTTTGAGAC & CTGTTTCTGCTGGTTGCGTA \\
TRAF6 & AGGGTACAATACGCCTCACG & GCGGGTAGAGACTTCACAGC \\
GADPH & CTCAGACACCATGGGGAAGGTGA & ATGATCTTGAGGCTGTTGTCATA \\
\hline
\end{tabular}

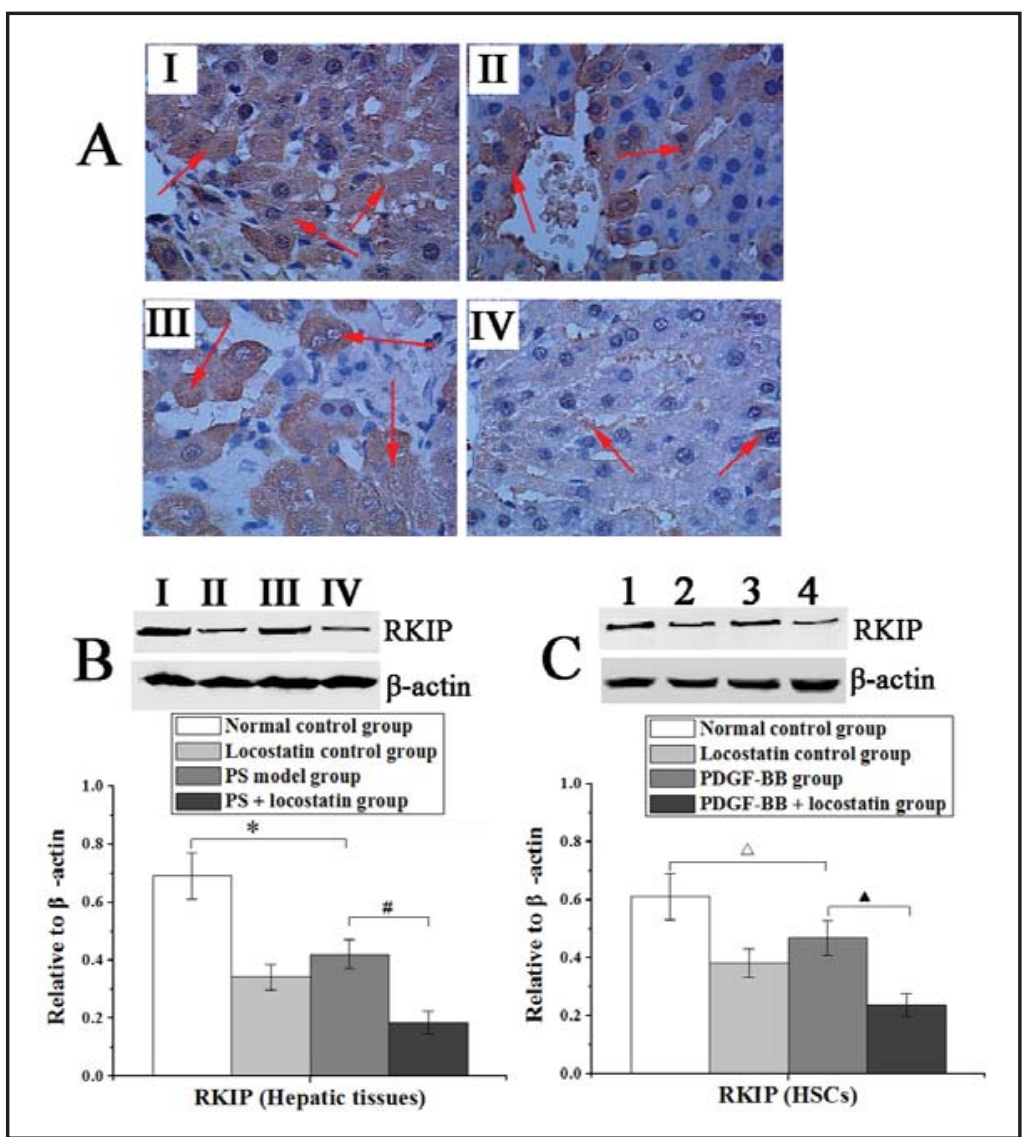

Fig. 1. The expression of RKIP in hepatic tissues and HSCs. (A) The distribution and expression of RKIP were examined by immunohistochemical analysis (400×); the arrows indicate the positive staining (brown). (B and C) The expression of RKIP in hepatic tissues and primary HSCs was detected by Western blotting, respectively. I to IV represented the normal control group, the locostatin control group, the porcine serum (PS) model group and the PS + locostatin group, respectively. The bands 1 to 4 represented the normal control cells, the locostatin control cells, the PDGF-BB-treated cells and the PDGF-BB + locostatin-treated cells, respectively. ${ }^{*} P<0.05$ vs. the normal control group; ${ }^{\#} P<0.05$ vs. the PS model group; ${ }^{\triangle} P<0.05$ vs. the normal control cells; $\triangle P<$ 0.05 vs. the PDGF-BB-treated cells. 


\section{Cellular Physiology Cell Physiol Biochem 2016;40:49-61 \begin{tabular}{ll|l} 
and Biochemist 10.1159/000452524 & $\begin{array}{l}\text { O } 2016 \text { The Author(s). Published by S. Karger AG, Basel } \\
\text { www.karger.com/cpb }\end{array}$ \\
\hline
\end{tabular} Huang et al.: Role of RKIP in Hepatic Fibrosis}

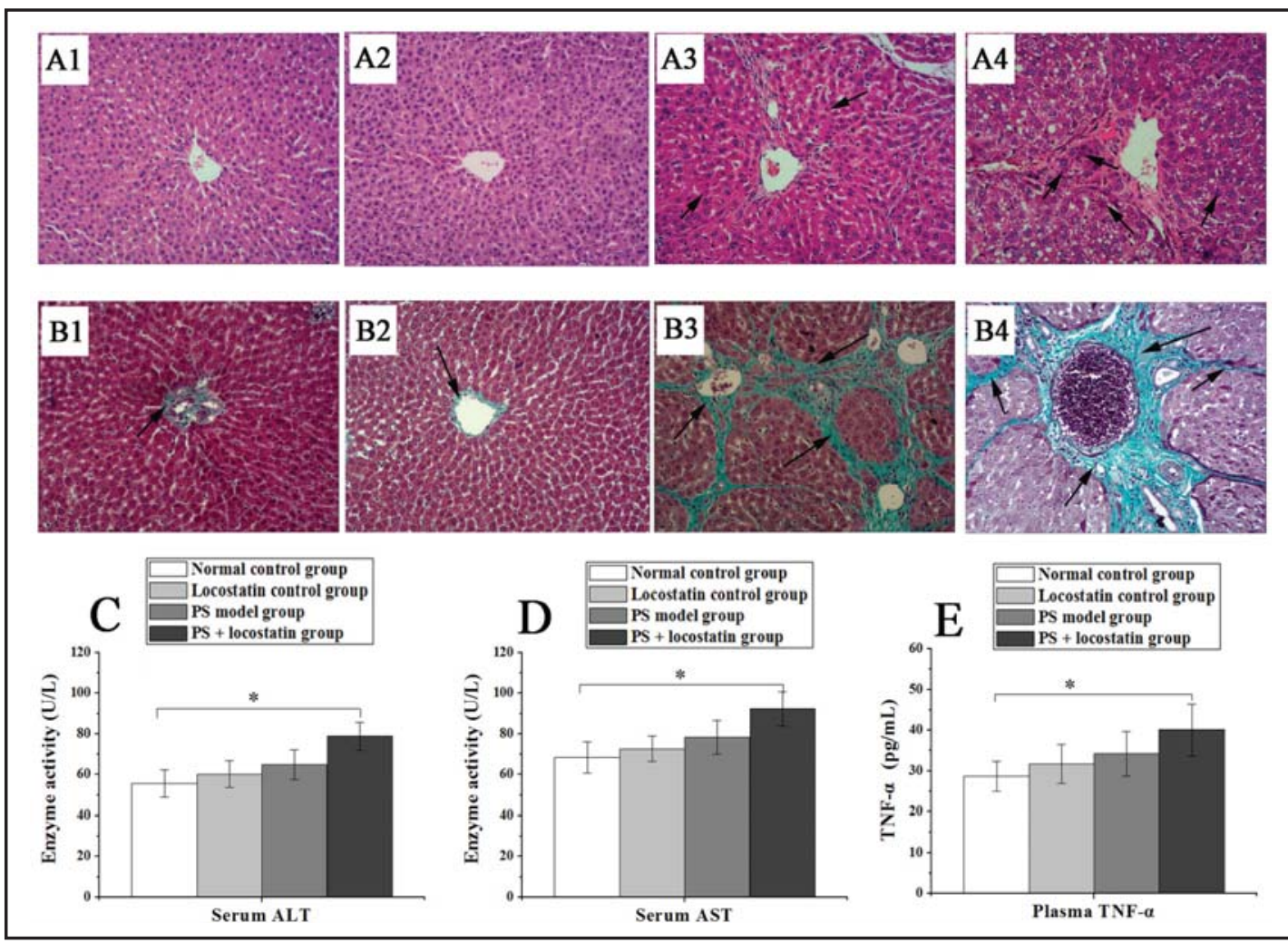

Fig. 2. Down-regulating RKIP expression aggravated histopathological injury. (A) Hematoxylin and eosin (H\&E) staining and (B) Masson's trichrome staining of the liver slices (200x). A1 and B1: normal control group; A2 and B2: locostatin control group; A3 and B3: PS model group; A4 and B4: PS + locostatin group. The arrows indicate hepatocellular necrosis in the H\&E staining and collagen fibers in the Masson's trichrome staining, respectively. (C and D) Serum ALT and AST were detected using commercial kits. (E) Plasma TNF- $\alpha$ was detected by ELISA test. ${ }^{*} P<0.05$ vs. the normal control group.

Moreover, Western blot showed that the expression of RKIP was significantly inhibited by locostatin in liver tissues in vivo and in primary HSCs in vitro (Fig. $1 \mathrm{~B}$ and C).

Decrease in RKIP expression exacerbated liver injury and collagen deposition

As shown in Fig. 2A. H\&E staining showed that the structure of the liver tissue was normal in the normal and locostatin control groups, with no obvious changes in the histology (Fig. 2 A1 and A2). PS caused slight liver injury, a small number of inflammatory cells were found around the portal area and central vein, without serious hepatocyte necrosis (Fig. 2 A3). However, hepatic turbidity, mild inflammatory infiltration and ballooning degeneration were observed in the PS + locostatin group (Fig. 2 A4).

In addition, Masson's trichrome staining showed that the livers from the normal and locostatin control groups showed traces of collagen only in the walls of major blood vessels (Fig. 2 B1 and B2). Compared to the normal control group, PS administration resulted in extensive accumulation of collagen in the liver tissues (Fig. 2 B3). Furthermore, the deposition of collagen in the PS + locostatin group was even more serious than that of the PS model group (Fig. 2 B4).

Decrease in RKIP expression increased the levels of ALT, AST and TNF- $\alpha$

Our results showed that the activities of serum AST and ALT were increased in the PS model group compared to the normal control group, but the difference did not show statistical significance. Treatment with PS plus locostatin significantly increased serum AST and ALT activities (Fig. 2 C and D). Additionally, locosatin significantly increased the content of TNF- $\alpha$ in the liver tissues of rats with hepatic fibrosis (Fig. $2 \mathrm{E}$ ). 


\section{Cellular Physiology Cell Physiol Biochem 2016;40:49-61 \begin{tabular}{ll|l} 
and Biochemistry & Dublished online: November 14, 2016 & $\begin{array}{l}\text { O } 2016 \text { The Author(s). Published by S. Karger AG, Basel } \\
\text { www.karger.com/cpb }\end{array}$ \\
\hline
\end{tabular} Huang et al.: Role of RKIP in Hepatic Fibrosis}

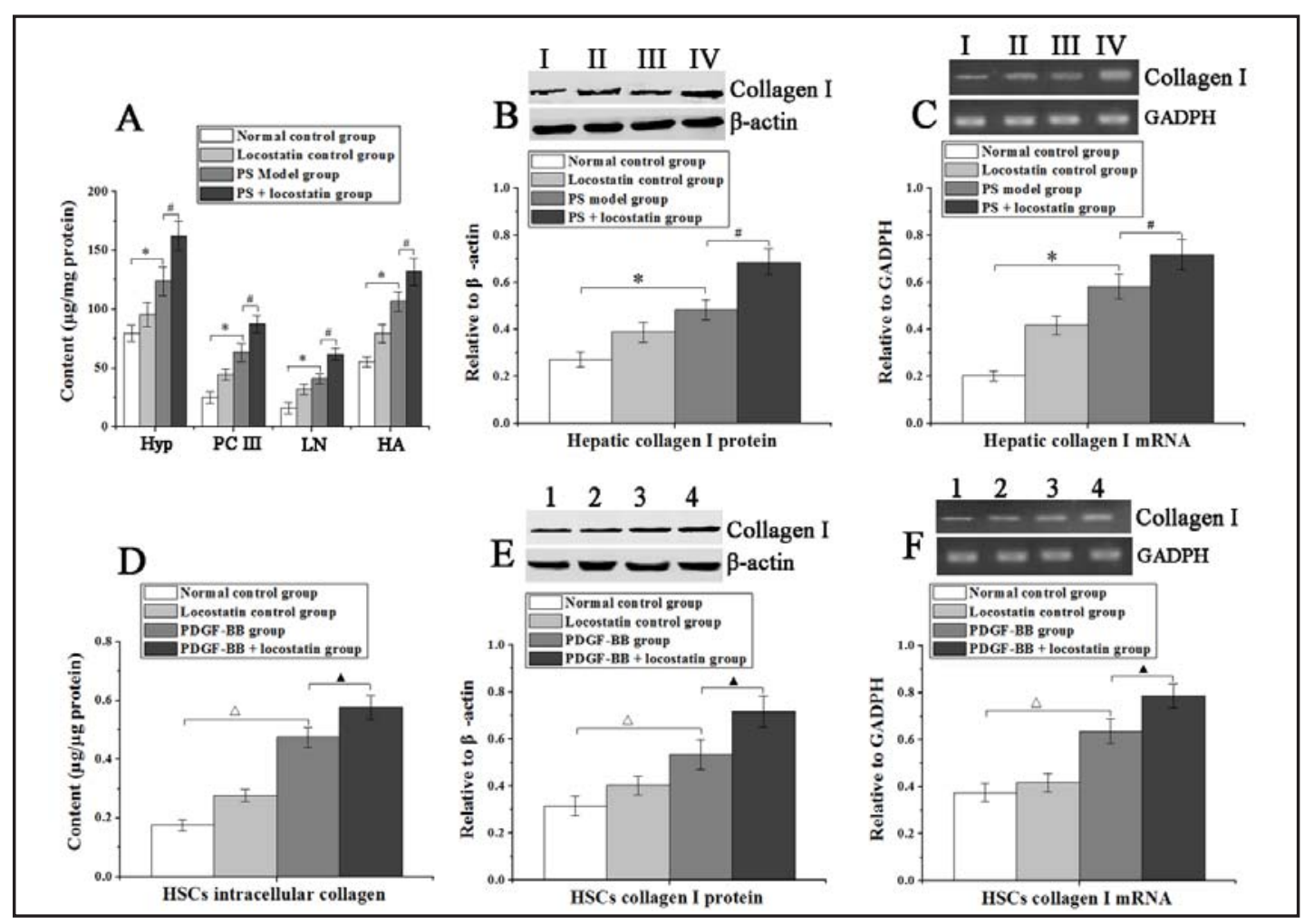

Fig. 3. Down-regulating RKIP expression increased the production of collagen in hepatic tissues and HSCs. The bands I to IV represented the normal control group, the locostatin control group, the PS model group and the PS + locostatin group, respectively. The bands 1 to 4 represented the normal control cells, the locostatin control cells, the PDGF-BB-treated cells and the PDGF-BB + locostatin-treated cells, respectively. ${ }^{*} P<0.05$ vs. the normal control group; ${ }^{\#} P<0.05$ vs. the PS model group; ${ }^{\triangle} P<0.05$ vs. the normal control cells; $\triangle P<0.05$ vs. the PDGF-BB-treated cells.

Decrease in RKIP expression increased the levels of collagen-related indicators in liver tissues

The key collagen-related indicators including hepatic Hyp, PCIII, LN and HA were determined in this study. As shown in Fig. 3A, the contents of these indicators in the PS model group were significantly increased compared to the normal control group. Importantly, the contents of these indicators in the PS + locostatin group were increased more obviously than those of the PS model group.

Decrease in RKIP expression promoted collagen accumulation in liver tissues and HSCs

Excessive collagen is an important characteristic feature of hepatic fibrosis. Our results showed that down-regulating RKIP expression significantly increased both the protein and mRNA expression of collagen I in liver tissues (Fig. 3B and C). Moreover, the cell experiment in vitro was also showed that absence of RKIP led to significant increase in the amount of intracellular collagen and the protein and mRNA expression of collagen I (Fig. 3D to F).

Decrease in RKIP expression promoted HSCs proliferation and colony formation

As shown in Fig. 4A, locostatin markedly promoted HSCs proliferation compared to the PDGF-BB group. Additionally, locostatin administration significantly increased the size and number of colonies of primary HSCs (Fig. 4B).

Decrease in RKIP expression increased $\alpha$-SMA levels in liver tissues and HSCS

Elevation of $\alpha$-SMA is a hallmark for activated HSCs [20]. As shown in Fig. 4C to F, compared to the normal control, down-regulating RKIP expression led to significant increases in the protein and mRNA expression of $\alpha$-SMA in vivo and in vitro. 


\section{Cellular Physiology Cell Physiol Biochem 2016;40:49-61

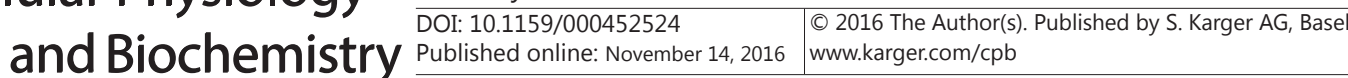

Fig. 4. Down-regulating RKIP expression promoted HSCs proliferation and colony formation, and increased the expression of $\alpha$-SMA in hepatic tissues and primary HSCs. The bands I to IV represented the normal control group, the locostatin control group, the PS model group and the PS + locostatin group, respectively. The bands 1 to 4 represented the normal control cells, the locostatin control cells, the PDGF-BB-treated cells and the PDGF-BB + locostatin-treated cells, respectively. $\quad{ }^{*} P<0.05$ vs. the normal control group; ${ }^{\#} P<0.05$ vs. the PS model group; ${ }^{\triangle} P<0.05$ vs. the normal control cells; $\triangle P<0.05$ vs. the PDGF-BB-treated cells.
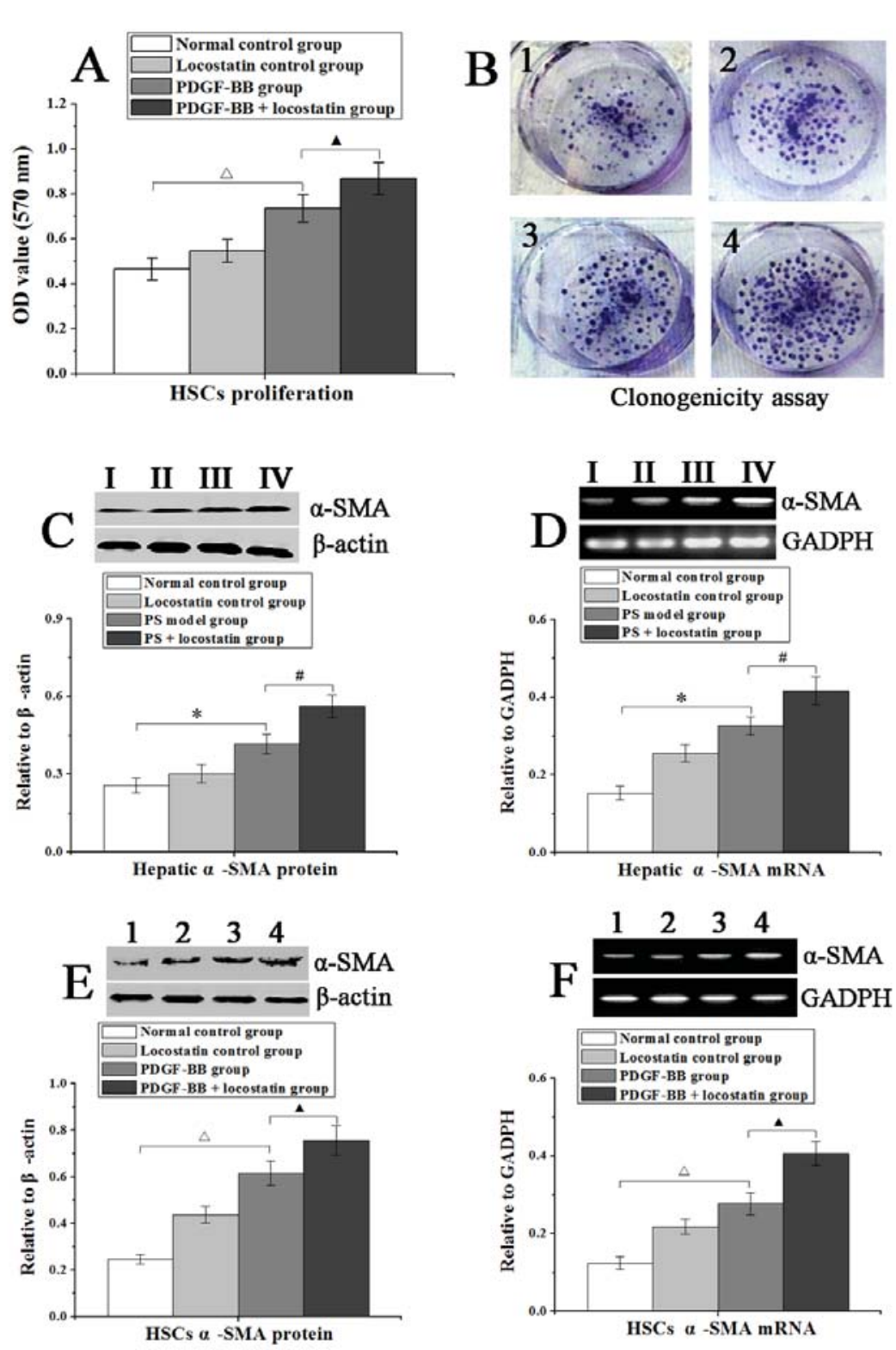

Decrease in RKIP expression increased the expression of matrix metalloproteinases

As shown in Fig. 5A and B, compared to the PS model group, treatment with locostatin significantly increased the protein and mRNA expression of MMP-1 and MMP-2 in the liver tissues. Similarly, locostatin notably enhanced both the matrix metalloproteinases levels in HSCs (Fig. 5C and D).

\section{Decrease in RKIP expression induced ERK pathway activation}

Immunohistochemical analysis showed that ERK protein was predominantly localized in the portal area. Compared to the PS model group, the positive cells intensity of ERK and p-ERK were significantly increased in the PS + locostatin group (Fig. 6A). Western blot revealed that the phosphorylation of Raf, ERK and MEK in the PS + locostatin group was higher than that of the PS model group (Fig. 6B). The cell experiment in vitro also showed that down-regulating RKIP led to significant increase in the dephosphorylation of Raf, ERK and MEK (Fig. 6C). These results indicate that decrease in RKIP expression is associated with the activation of the ERK pathway. 


\section{Cellular Physiology Cell Physiol Biochem 2016;40:49-61 \begin{tabular}{l|l|l} 
DOI: 10.1159/000452524 & $\begin{array}{l}\text { ( 2016 The Author(s). Published by S. Karger AG, Basel } \\
\text { www.karger.com/cpb }\end{array}$ \\
\hline
\end{tabular}

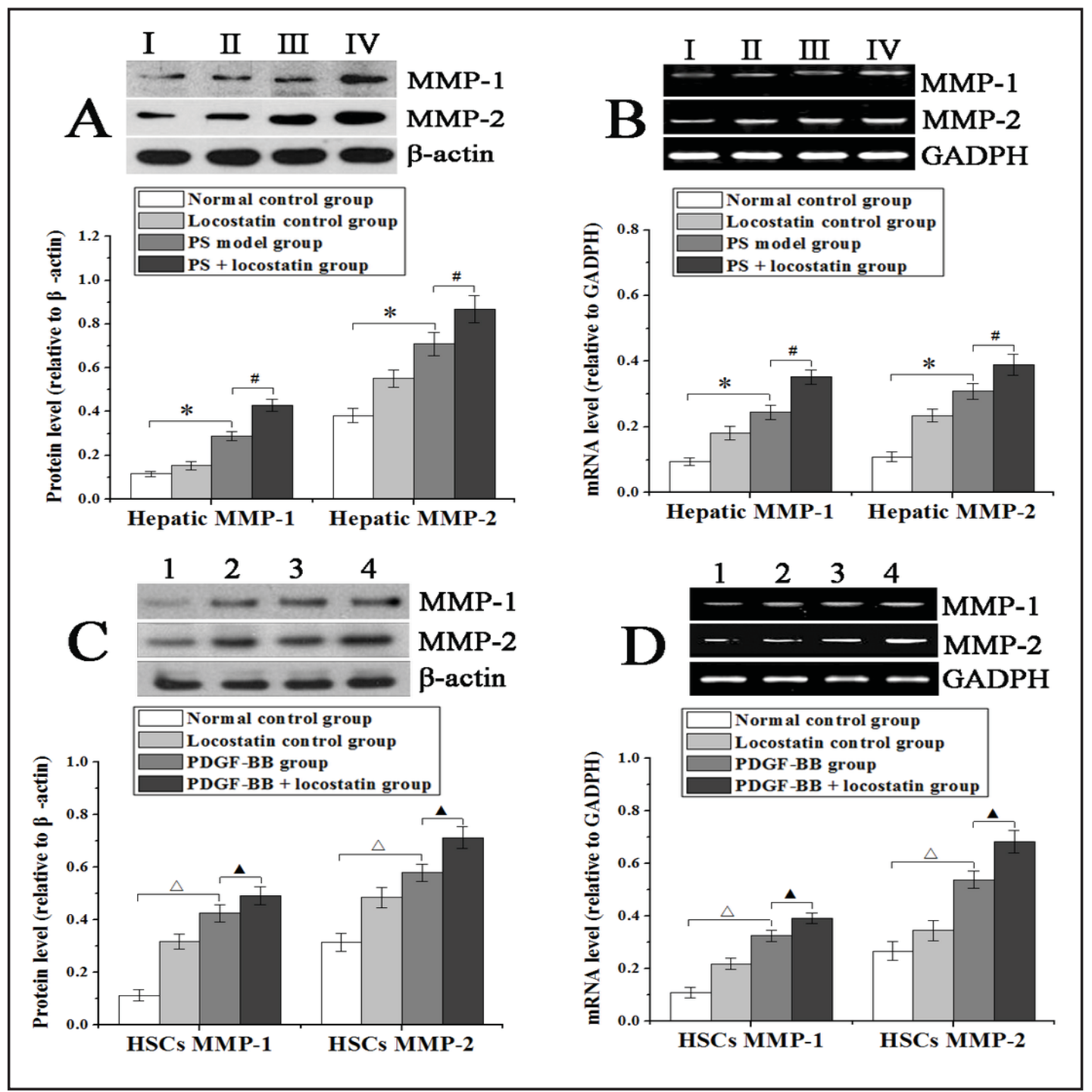

Fig. 5. Down-regulating RKIP expression increased the expression of MMP-1 and -2 in hepatic tissues and HSCs. The bands I to IV represented the normal control group, the locostatin control group, the PS model group and the PS + locostatin group, respectively. The bands 1 to 4 represented the normal control cells, the locostatin control cells, the PDGF-BB-treated cells and the PDGF-BB + locostatin-treated cells, respectively. ${ }^{*} P<0.05$ vs. the normal control group; ${ }^{\#} P<0.05$ vs. the PS model group; ${ }^{\triangle} P<0.05$ vs. the normal control cells; $\triangle P<0.05$ vs. the PDGF-BB-treated cells.

Decrease in RKIP expression enhanced the TLR4 pathway activation

To fully understand the role of RKIP in hepatic fibrosis, the important intracellular TLR4 signaling pathway was investigated. As shown in Fig. 7, compared to the PS model control, locostatin treatment significantly increased the protein expression of TLR4 and the mRNA levels of TLR4, MyD88 and TRAF6, suggesting that down-regulating RKIP induced TLR4 pathway activation.

\section{Discussion}

RKIP is widely expressed in normal human tissues and has been considered as an important regulator of several physiologic processes [21]. Several studies have demonstrated 


\section{Cellular Physiology Cell Physiol Biochem 2016;40:49-61 \begin{tabular}{ll|l} 
and Biochemistry & DOI: 10.1159/000452524 & ( 2016 The Author(s). Published by S. Karger AG, Basel \\
\cline { 1 - 3 }
\end{tabular}

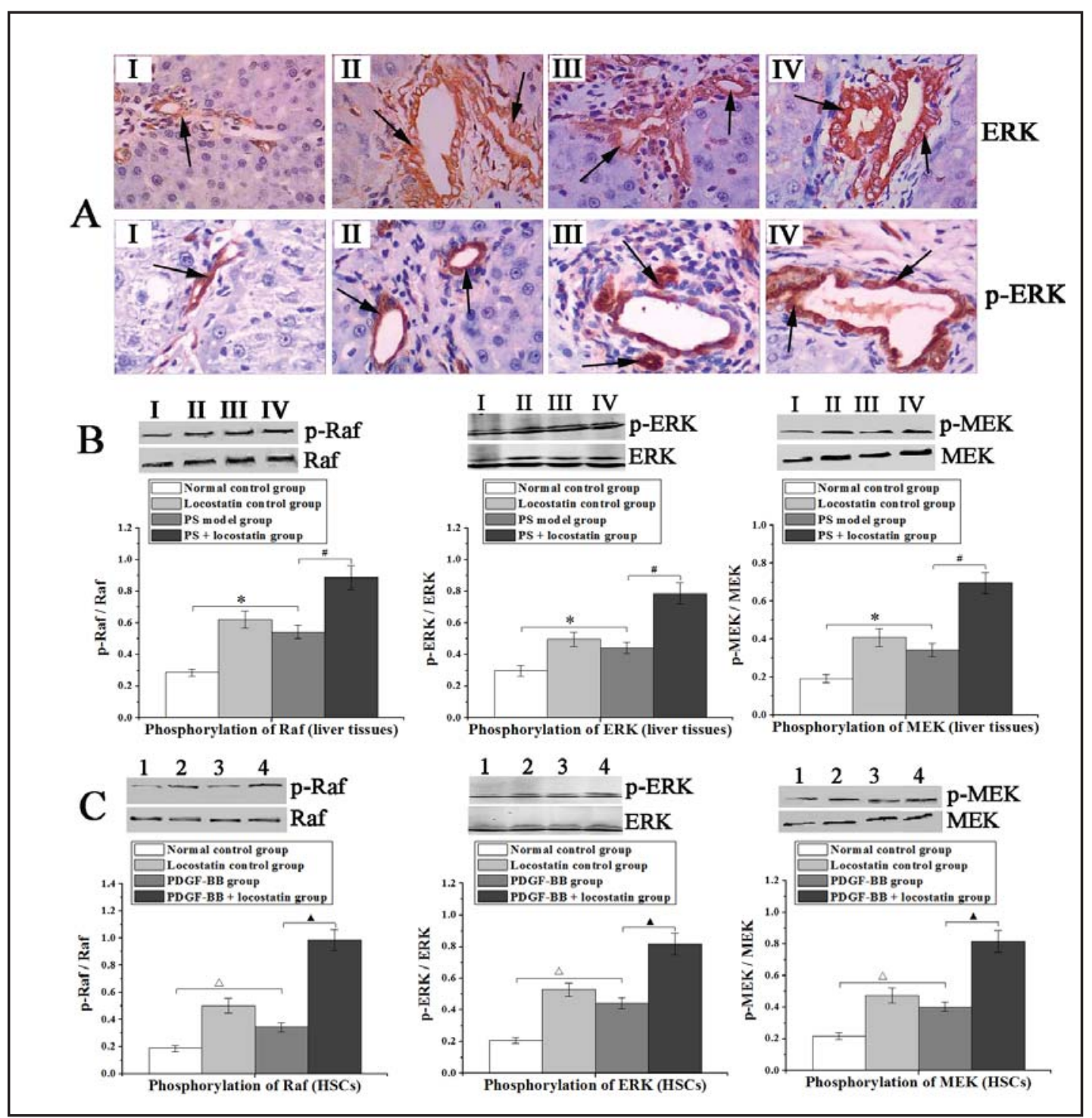

Fig. 6. Down-regulating RKIP expression induced the activation of ERK pathway in hepatic tissues and HSCs. (A) immunohistochemical (IHC) staining of ERK and p-ERK in liver tissues (400×, the arrows indicate the positive staining); (B) the phosphorylation of Raf, ERK and MEK in hepatic tissues; (C) the phosphorylation of Raf, ERK and MEK in HSCs. The bands I to IV represented the normal control group, the locostatin control group, the PS model group and the PS + locostatin group, respectively. The bands 1 to 4 represented the normal control cells, the locostatin control cells, the PDGF-BB-treated cells and the PDGF-BB + locostatin-treated cells, respectively. ${ }^{*} P<0.05$ vs. the normal control group; ${ }^{\#} P<0.05$ vs. the PS model group; ${ }^{\triangle} P<$ 0.05 vs. the normal control cells; $\wedge<<0.05$ vs. the PDGF-BB-treated cells.

that RKIP was closely associated with numerous tumors and participated in their occurrence and development; it could regulate the growth, apoptosis, invasion and metastasis of tumor cells [22]. However, the role of RKIP in chronic liver injury and particularly in liver fibrosis is still unclear. We hypothesized that RKIP may play a key role in the molecular pathogenesis of liver fibrosis because loss of RKIP would contribute to the activation of the ERK/MAPK pathway which is involved in cell growth, differentiation and migration of HSCs during liver fibrosis. Thus, in the present study, RKIP expression was interfered by locostatin, and its biological role in liver fibrosis was investigated in vivo and in vitro. 


\section{Cellular Physiology Cell Physiol Biochem 2016;40:49-61 \begin{tabular}{l|l|l} 
DOI: 10.1159/000452524 & $\begin{array}{l}\text { ( 2016 The Author(s). Published by S. Karger AG, Basel } \\
\text { www.karger.com/cpb }\end{array}$ \\
\hline
\end{tabular}}
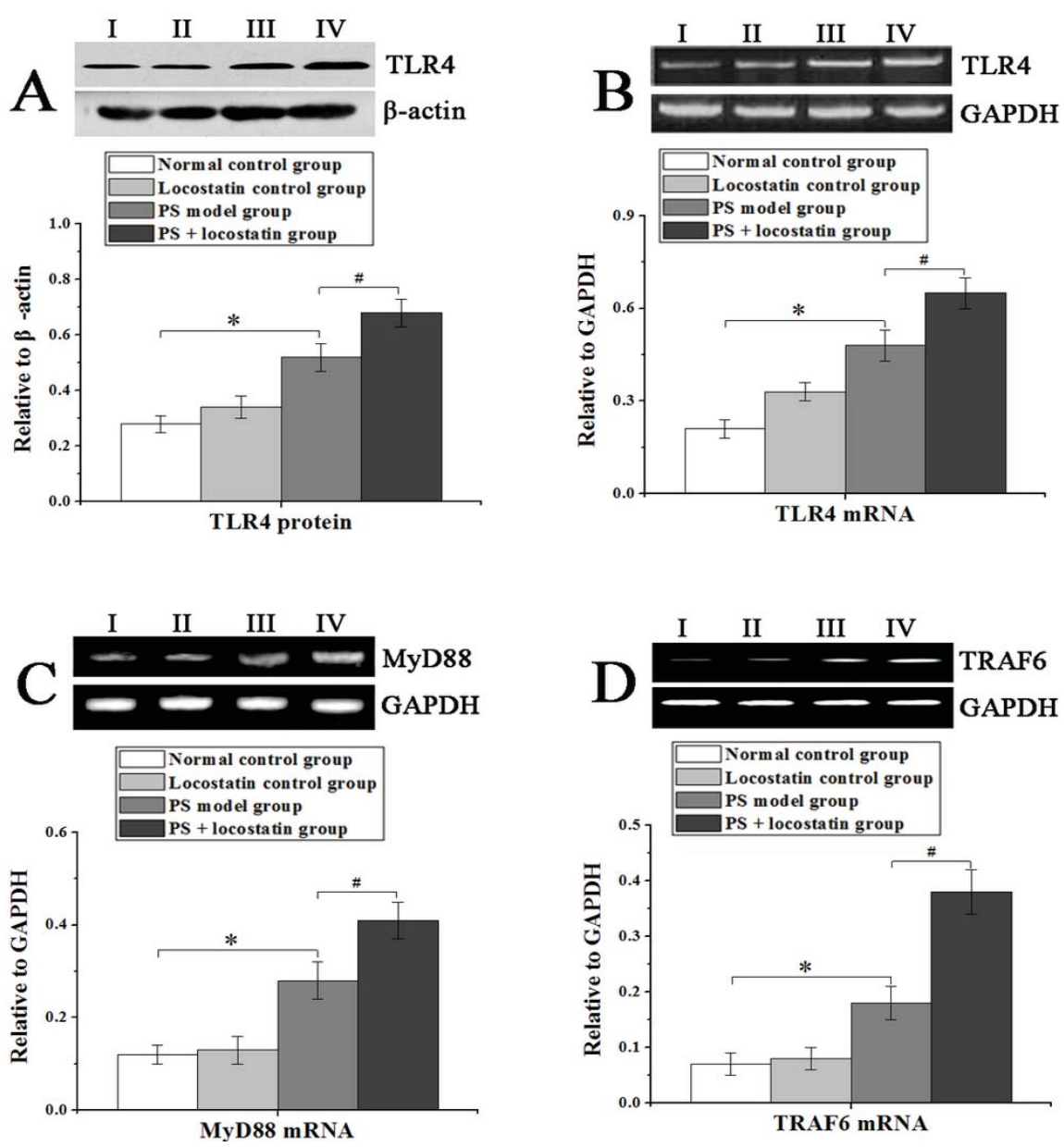

Fig. 7. Down-regulating RKIP expression enhanced the activation of TLR4 pathway. The bands I to IV represented the normal control group, the locostatin control group, the PS model group and the PS + locostatin group, respectively. ${ }^{*} P<0.05$ vs. the normal control group; ${ }^{\#} P<0.05$ vs. the PS model group.

PS-induced hepatic fibrosis is mainly the consequence of intense immune response with mild hepatic damage. This immunological response is regulated by MHC class II molecules and inflammatory cells, which activate HSC-producing liver fibrosis [23]. In this study, we observed that treatment with PS plus locostatin led to serious liver injury. Moreover, the levels of ALT, AST and TNF- $\alpha$ in the PS + locostatin group were significantly increased compared to the PS model group. In addition, locostatin administration resulted in extensive accumulation of collagen in liver tissues. The contents of the collagen-related indicators including hepatic Hyp, PCIII, LN and HA were higher in the PS + locostatin group than those of the PS model group. Furthermore, the protein and mRNA expression of collagen I and $\alpha$-SAM was notably increased in the PS + locostatin group. These results indicate an inverse correlation between RKIP expression and the degree of the liver injury and fibrosis.

Activation of HSCs plays a key role in hepatic fibrogenesis, since these cells are the principal cellular source of the excess collagen synthesis during hepatic fibrosis [24]. In the present study, we observed that down-regulating RKIP expression significantly promoted HSCs proliferation and colony formation, which suggests that RKIP plays an important role in the HSCs proliferation. In addition, our study showed that the amount of intracellular collagen, both the protein and mRNA expression of collagen I and $\alpha$-SMA were significantly increased after down-regulating RKIP expression. These results indicate that decrease in 


\section{Cellular Physiology Cell Physiol Biochem 2016;40:49-61 \\ \begin{tabular}{ll|l} 
and Biochem 10.1159/000452524 & $\begin{array}{l}\text { @ 2016 The Author(s). Published by S. Karger AG, Basel } \\
\text { www.karger.com/cpb }\end{array}$ \\
\hline
\end{tabular} \\ Huang et al.: Role of RKIP in Hepatic Fibrosis}

RKIP expression promotes the accumulation of collagen and the activation of HSCs.

During hepatic fibrogenesis, the expression of the matrix metalloproteinases (MMPs) involved in fibrillar collagen degradation is very limited, whereas the expression of MMP-2 is markedly increased [25]. MMP-2 has been implicated in ECM turnover; in particular, it can degrade several components of the subendothelial matrix, including collagen IV, laminin and fibronectin, and it may be important in the remodeling of matrix during tissue repair processes [26]. It has been reported that RKIP prevents the invasion of cancer cells by controlling the expression of matrix metalloproteinases (MMPs), particularly MMP-1 and MMP-2 [27]. In the present study, we observed that locostatin significantly increased the protein and mRNA expression of MMP-1 and MMP-2 in liver tissues and HSCs. This result indicates that absence of RKIP promotes HSCs proliferation partly by enhancing MMP-1 and MMP-2 expression.

It is likely that RKIP regulates HSCs proliferation due to the regulation of the ERK signaling pathway. The ERK/MAPK signaling pathway is involved in cell growth, differentiation and migration of HSCs during liver fibrosis. The phosphorylation of Raf- 1 and ERK is one of the signal pathways in HSCs that leads to its activation and proliferation, which are fundamental steps in liver fibrogenesis. As long as the ERK/MAPK pathway is suppressed, HSCs activation and proliferation should be restrained. RKIP was originally identified as a scaffolding protein, which inhibits the function of Raf-1 [28]. Over-expression of RKIP inhibits MEK, ERK and Ap-1 transcription factor activity. In contrast, inhibition of RKIP stimulates MEK, ERK and Ap-1 activity. Phosphorylation of RKIP on S153 by protein kinase C71 or ERK72 results in dissociation of RKIP from Raf- 1 and relief of RKIP's suppressive effects on Raf-1 [29]. In this study, to further understand the role of RKIP in liver fibrosis, we investigated the relationship between RKIP and the ERK/MAPK signaling pathways in vitro and in vivo. The immunohistochemical staining and the Western blot analysis showed that in the PS + locostatin group, the expression of RKIP was lower, whereas the phosphorylation of Raf, ERK and MEK was higher than that of the PS model group; and similar results were found in HSCs in vitro. The data showed an inverse correlation between RKIP expression level and Raf/ ERK/MEK phosphorylation in liver tissues and primary HSCs. These results suggest that loss of RKIP cancels its inhibitory effect on the ERK/MAPK pathway, resulting in the activation and proliferation of HSCs and even the development of hepatic fibrosis.

To elucidate the molecular mechanism by which RKIP modulated hepatic inflammatory response, we further investigated the role of toll-like receptors (TLRs) signaling pathway. TLRs belong to a large family of transmembrane proteins that recognize pathogen-associated molecular patterns (PAMPs) and are involved in innate immune responses [30]. TLRs play an important role in liver pathophysiology and chronic liver diseases, since the liver is constantly exposed to a high amount of PAMPs [31]. Hepatic fibrosis and cirrhosis have been linked to TLRs (especially TLR4) [32]. In the present study, we observed that down-regulating RKIP expression significantly increased the expression of TLR4 protein and the mRNA expression levels of TLR4, MyD88 and TRAF6. Thus, it is possible that loss of RKIP exacerbates hepatic fibrosis, at least in part, through the activation of the TLR4 signaling pathway.

\section{Conclusion}

Our results showed an inverse correlation between RKIP expression and the degree of the liver injury and fibrosis, that is, loss of RKIP is associated with malignant progression in hepatic fibrosis.

\section{Acknowledgments}

The authors gratefully acknowledge the financial support provided by the National Natural Science Foundation of China (No. 81260505) and the Guangxi Natural Science Foundation (2013GXNSFAA019150; 2014GXNSFAA118154). 


\section{Cellular Physiology Cell Physiol Biochem 2016;40:49-61 \begin{tabular}{ll|l}
\cline { 2 - 2 } and Biochemist 10.1159/000452524 & $\begin{array}{l}\text { @ 2016 The Author(s). Published by S. Karger AG, Basel } \\
\text { www.karger.com/cpb }\end{array}$ \\
\hline
\end{tabular} \\ Huang et al.: Role of RKIP in Hepatic Fibrosis}

\section{Disclosure Statement}

The authors declare that there are no conflicts of interest.

\section{References}

1 Friedman SL: Mechanisms of hepatic fibrogenesis. Gastroenterology 2008;134:1655-1669.

2 Zhang X, Tan Z, Wang Y, Tang J, Jiang R, Hou J, Zhuo H, Wang X, Ji J, Qin X, Sun B: Ptpro-associated hepatic stellate cell activation plays a critical role in liver fibrosis. Cell Physiol Biochem 2015;35:885-898.

3 Tacke F, Weiskirchen R: Update on hepatic stellate cells: Pathogenic role in liver fibrosis and novel isolation techniques. Expert Rev Gastroenterol Hepatol 2012;6:67-80.

4 Marra F, Delogu W, Petrai I, Pastacaldi S, Bonacchi A, Efsen E, Aleffi S, Bertolani C, Pinzani M, Gentilini P: Differential requirement of members of the mapk family for ccl2 expression by hepatic stellate cells. Am J Physiol Gastrointest Liver Physiol 2004;287:G18-G26.

5 Serre L, de Jesus KP, Zelwer C, Bureaud N, Schoentgen F, Bénédetti H: Crystal structures of ybhb and ybcl from escherichia coli, two bacterial homologues to a raf kinase inhibitor protein. J Mol Biol 2001;310:617634.

6 Yeung K, Seitz T, Li S, Janosch P, McFerran B, Kaiser C, Fee F, Katsanakis KD, Rose DW, Mischak H: Suppression of raf-1 kinase activity and map kinase signalling by rkip. Nature 1999;401:173-177.

7 Liu H, Wei W, Sun W-y, Li X: Protective effects of astragaloside iv on porcine-serum-induced hepatic fibrosis in rats and in vitro effects on hepatic stellate cells. J Ethnopharmacol 2009;122:502-508.

8 Abdelazim SA, Darwish HA, Ali SA, Rizk MZ, Kadry MO: Potential antifibrotic and angiostatic impact of idebenone, carnosine and vitamin e in nano-sized titanium dioxide-induced liver injury. Cell Physiol Biochem 2015;35:2402-2411.

9 Wei Y, Huang M, Liu X, Yuan Z, Peng Y, Huang Z, Duan X, Zhao T: Anti-fibrotic effect of plumbagin on ccl4lesioned rats. Cell Physiol Biochem 2015;35:1599-1608.

10 Benyon RC, Hovell CJ, Da Gaça M, Jones EH, Iredale JP, Arthur MJ: Progelatinase a is produced and activated by rat hepatic stellate cells and promotes their proliferation. Hepatology 1999;30:977-986.

11 Gong XH, Chen C, Hou P, Zhu SC, Wu CQ, Song CL, Ni W, Hu JF, Yao DK, Kang JH, Zhu L: Overexpression of mir-126 inhibits the activation and migration of hscs through targeting crk. Cell Physiol Biochem 2014;33:97-106.

12 Ma J, Li F, Liu L, Cui D, Wu X, Jiang X, Jiang H: Raf kinase inhibitor protein inhibits cell proliferation but promotes cell migration in rat hepatic stellate cells. Liver Int 2009;29:567-574.

13 Patsenker E, Popov Y, Wiesner M, Goodman SL, Schuppan D: Pharmacological inhibition of the vitronectin receptor abrogates pdgf-bb-induced hepatic stellate cell migration and activation in vitro. J Hepatol 2007;46:878-887.

14 Xiao Y, Qu C, Ge W, Wang B, Wu J, Xu L, Chen Y: Depletion of thymosin $\beta 4$ promotes the proliferation, migration, and activation of human hepatic stellate cells. Cell Physiol Biochem 2014;34:356-367.

15 Li B, Shao Q, Ji D, Li F, Chen G: Mesenchymal stem cells mitigate cirrhosis through bmp7. Cell Physiol Biochem 2015;35:433-440.

16 Tullberg-Reinert H, Jundt G: In situ measurement of collagen synthesis by human bone cells with a sirius red-based colorimetric microassay: Effects of transforming growth factor $\beta 2$ and ascorbic acid 2-phosphate. Histochem Cell Biol 1999;112:271-276.

17 Jia S, Liu X, Li W, Xie J, Yang L, Li L: Peroxisome proliferator-activated receptor gamma negatively regulates the differentiation of bone marrow-derived mesenchymal stem cells toward myofibroblasts in liver fibrogenesis. Cell Physiol Biochem 2015;37:2085-2100.

18 Ji D, Li B, Shao Q Li F, Li Z, Chen G: Mir-22 suppresses bmp7 in the development of cirrhosis. Cell Physiol Biochem 2015;36:1026-1036.

19 Cui L, Hu Y, Bai B, Zhang S: Serum mir-335 level is associated with the treatment response to trans-arterial chemoembolization and prognosis in patients with hepatocellular carcinoma. Cell Physiol Biochem 2015;37:276-283. 


\section{Cellular Physiology Cell Physiol Biochem 2016;40:49-61 \begin{tabular}{c|l|l} 
DOI: 10.1159/000452524 & O 2016 The Author(s). Published by S. Karger AG, Basel \\
and Biochemistry.karger.com/cpb
\end{tabular} \\ Huang et al.: Role of RKIP in Hepatic Fibrosis}

20 Radaeva S, Sun R, Jaruga B, Nguyen VT, Tian Z, Gao B: Natural killer cells ameliorate liver fibrosis by killing activated stellate cells in nkg2d-dependent and tumor necrosis factor-related apoptosis-inducing liganddependent manners. Gastroenterology 2006;130:435-452.

21 Keller ET, Fu Z, Brennan M: The role of raf kinase inhibitor protein (RKIP) in health and disease. Biochem Pharmacol 2004;68:1049-1053.

22 Zhao D, Ma J, Shi J, Cheng L, Li F, Jiang X, Jiang H: Raf kinase inhibitor protein inhibits esophageal cancer cell invasion through downregulation of matrix metalloproteinase expression. Oncol Rep 2013;30:304-312.

23 Hasegawa-Baba Y, Doi K: Changes in timp-1 and-2 expression in the early stage of porcine serum-induced liver fibrosis in rats. Exp Toxicol Pathol 2011;63:357-361.

24 Friedman SL: Stellate cells: A moving target in hepatic fibrogenesis. Hepatology 2004;40:1041-1043.

25 Milani S, Herbst H, Schuppan D, Grappone C, Pellegrini G, Pinzani M, Casini A, Calabro A, Ciancio G, Stefanini F, et al.: Differential expression of matrix-metalloproteinase- 1 and -2 genes in normal and fibrotic human liver. Am J Pathol 1994;144:528-537.

26 Préaux AM, Mallat A, Van Nhieu JT, d'Ortho MP, Hembry RM, Mavier P: Matrix metalloproteinase-2 activation in human hepatic fibrosis regulation by cell-matrix interactions. Hepatology 1999;30:944-950.

27 Beshir AB, Ren G, Magpusao AN, Barone LM, Yeung KC, Fenteany G: Raf kinase inhibitor protein suppresses nuclear factor-kb-dependent cancer cell invasion through negative regulation of matrix metalloproteinase expression. Cancer Lett 2010;299:137-149.

28 Klysik J, Theroux SJ, Sedivy JM, Moffit JS, Boekelheide K: Signaling crossroads: The function of raf kinase inhibitory protein in cancer, the central nervous system and reproduction. Cell Signal 2008;20:1-9.

29 Hagan S, Garcia R, Dhillon A, Kolch W: Raf kinase inhibitor protein regulation of raf and mapk signaling. Methods Enzymol 2006;407:248-259.

30 Medzhitov R, Preston-Hurlburt P, Janeway CA, Jr.: A human homologue of the drosophila toll protein signals activation of adaptive immunity. Nature 1997;388:394-397.

31 Seki E, Brenner DA: Toll-like receptors and adaptor molecules in liver disease: Update. Hepatology 2008;48:322-335.

32 Seki E, De Minicis S, Osterreicher CH, Kluwe J, Osawa Y, Brenner DA, Schwabe RF: Tlr4 enhances tgf-beta signaling and hepatic fibrosis. Nat Med 2007;13:1324-1332. 